\title{
De falas soltas e fragmentos... tecendo histórias de mulheres em Joinville no século XIX
}

Tensões, trabalhos e sociabilidades: histórias de mulheres em J oinville no século XIX.

SILVA, J a nine Gomes da.

J oinville, SC: Ed. UNIVILE, 2004. 225 p.

Histórias de mulheres, relações de gênero, as práticas de memória, as mulherese as relações de gênero na construção de uma cida de - essas são questões que se colocam ao longo do livro de Janine Gomes da Silva intitulado Tensões, trabalhos e sociabilida des: histórias de mulheres em J oinville no século XIX.

Inicialmente, esse livro foi escrito como dissertação de mestrado, defendida junto ao Programa de Pós-Graduação em História da Universidade Federal de Santa Catarina (UFSC), em dezembro de 1997. A autora é doutora em História pela Universidade Federal de Santa Catarina (UFSC), professora do Departa mento de História da Universidade da Região de Joinville (UNIVILE) e historiadora do Arquivo Histórico de Joinville.

Em meio a interlocuções com as historiografias loca is e, especialmente, em aspectos da invisibilidade feminina que estas operam, Janine esc reve histórias de mulheres em Joinville ${ }^{1}$ no século XIX. ${ }^{2}$ Ressalta outros fios condutores, ta is como a formação da cidade e as tensões entre luso-brasileirose imigrantes, que foram se (re)desenhand o ao longo do estudo. Nas palavras da autora, "de uma primeira intenção, que era a da questão da visibilidade feminina por si só importante por trazer à tona um tema pouco problematizado na historia oral -, somaram-se outros fios condutores" (p. 13).

Os imigrantes, nesse caso, alemães, em maior número, colonizaram J oinville a partir de 1851. Como pano de fundo do estudo, em relação à formação da cidade, Janine destaca as vivências, os trabalhos, os divertimentos, as poesias, as sociabilida desfemininas... 0 interesse da autora, a o estudar o cotidiano de Joinville desde sua fundação, em 1851, a té o final do século XIX, anuncia-se como expectativa de conhecer o "ainda não dito" sobre a história da cidade: o que, posteriomente, traduz-se, em vez de o "ainda não dito", como "falas soltas e fragmentos sobre as mulheres". É interessante observarque as informações, como um conjunto de falas soltas e fragmentos, obscurecem a visibilidade de possíveis relações que se estabeleciam entre os sujeitos e que não se restring iam às relações socia is imediatas.

Portanto, com o propósito de tecerhistórias, a autora se coloca a tarefa de articulardiferentes 
fontes, ta is como jomais da época, fotografias, diários de poesias, joma is de casamentos, obras sobre a história de Joinville, reminiscências de imigrantes desc end entes, entre outras. Vozes do passado são, pelo trabalho da historiadora, entrecruzadas no presente. De modo semelhante, em termos da diversidade, procede em relação à a ná lise, utilizando-se de estudos que tra ta $\mathrm{m} \mathrm{da}$ história das mulheres, das relações de gênero, da memória, do cotidiano, das sociabilidades, da historiografia local, da imigração, por meio de autores/as como Joan Scott, Michelle Perrot, Mic hel de Certeau, Maria Odila Leite da Silva Dias, Joana Maria Pedro, Giralda Seyferth, Marionilde Dias Brepohl de Magalhães, Philippe Ariès, Eric Hobsbawm, Carlos Ficker, Carlos Gomes de Oliveira, Apoliná rio Temes, Elly Herkenhoff, Marina Maluf, Ecléa Bosi, Miriam Moreira Leite, entre outros/as. Há que se considerar, no presente estudo, os olhares e diálogos datados que a tra vessa m os reg istros na esc rita dessa s histórias.

O livro divide-se em três capítulos. No primeiro, "Na tessitura de uma história - mulheres de Joinville e tensões entre brasileiros e imigrantes", a a utora ressa lta vivências cotidianas e faz referência ao mito fundador, presente nos registros da época e que diz respeito aosprimeiros imigrantes europeus. Pontua que os discursos a nunciavam "ha rmonia", "progresso", "ordem" e "trabalho", com base nos imigrantes alemães, enqua nto coloniza dores, em detrimento de outros imigrantes e dos próprios brasileiros, de modo a não interpretar as diferenças. Incluem-se aí disputas e desqualificações entre os grupos étnic os.

Há uma espécie de mito fundadorque valoriza os registros da época, acerca dos primeiros imigrantes e seu pioneirismo, contando e recontando a história a partir de 1851. Dentro dessa perspectiva, tal história inicia-se em 1851, quando chegaram a Joinville os primeiros imigrantes europeus. Alguns anos antes, algumas pessoas já haviam visitado a cidade para verificar o território e, posteriormente, para fazer demarcações, mas foi em 9/03/1851 que os primeiros imigrantes, vindos com a barca de Colon até o Porto de São Francisco, chegaram à Colônia Dona Francisca (p. 22).

Nesse sentido, as mulheres eram incluídas quando se falava genericamente dos imigrantes, dos pioneiros e dos homens, o que, de acordo com a autora, não parece contemplar suas participaçõesna construção da cidade. Presume, ta mbém, que, porpressão de uma nova elite que estava se constituindo, integrada por imigrantes e por famílias brasileiras envolvidas com o comércio da erva-mate, alguns periódicos a na lisa dos a nuncia vam "as condutas da mulher ideal". Questiona, contudo, se as joinvilenses correspondiam a essas mulheres idealizadas, a pontando para possibilida des de distanciamento entre a imagem construída e a realidade da cidade. Entre outras formas de desenhar comportamentos, em casa ou na escola. encontra vam-se, a inda, conteúdos educativos que se diferenciavam de acordo com os gêneros e sugeriam a divisão dos espaços público e priva do, os qua is, respectiva mente, destinavamse aos homens e às mulheres.

"Professoras, comerciantes, cozinheiras... - o trabalho das mulheres na construção de J oinville" compreende o título do segundo capítulo. Neste, a autora identific a o trabalho e suas vinculações às noções de progresso e de pioneirismo dos imigrantes, o que não contemplava "a grande massa de pessoas que ta mbém trabalhou" (p. 77). Inclui a valorização da história do trabalho urbano em comparação ao trabalho rural, e conclui que o progresso da cidade não poderia ser apenas atribuído aos empresários e comerciantes, pois a maior parte dos seus habitantes estava na área rural.

A a utora argumenta que o trabalho como foco da construção da cida de constituía a vida cotidiana doshomense mulheres joinvilenses. Isso, no entanto, ao ser registrado pela historiografia local, assumiu aspectos que privilegiaram os homens. Porém, como justifica, não se pode considerarque a "história contemple o cotidia no masculino, mas o fato de os trabalhos empreendidos pelos 'pioneiros' para desbravar a região e construir a cidade darem a tônica à referida historiografia faz dos homens sujeitos dessa história" (p. 65). Sobre esse enredo, a autora se dedica a uma análise para além do espaço doméstic 0 , articula ndo a disc ussão com ba se na divisão sexual do trabalho e sua historicidade.

De acordo com as fontes pesquisa das pela autora, as mulheres apareciam como esposas, mães, donas-de-casa, cozinheiras, comerciantes, professoras, parteiras, costureiras, operárias; transgrediam regras e ousavam circular nos espaços da casa e da rua. Com isso, a autora sublinha questões que ind ic am contra dições em torno da permanência de discursos sobre a inferiorida de dostrabalhosfemininose sua marca enquanto complemento ao orçamento doméstico.

No terceiro e último capítulo, a autora apresenta "As sociabilidades" e seus desd obramentos temátic os, orga niza dos a partir 
de informações que se impuseram à a nálise, isto é, o "cotidiano joinvilense do século XIX foi 'surg indo', mostrando suas redes de cumplic idade e seus conflitos" (p. 105). Trata-se do ca pítulo ma is longo do livro, em que a autora opera, de forma minuciosa, as informações que versam sobre práticas de sociabilidades de mulherese homens em Joinville, no século XIX, reveladoras de experiências cotidianas e de demarcadores étnicos. Nesse capítulo, circulam registros que permitem a dentrar os espaç os públic o e privado, especialmente, os entrelaçamentos que os compõem e que possibilita $m$ indagaracerca da tênue divisão que se coloca, simbolicamente desenhada em determinados tempos e lugares. Perseguindo pistas, a autora dispõe dos registros de poesias, de bailes, de corais, de peças de tea tro como fontes para a escrita dessa s histórias de sociabilidades, que convergem no (re)encontro de tradições, no estabelecimento e cultivo de novas redes de amizade na "nova terra".

Assim, diante do texto cuidadoso e artic ula do, a presenta do pela autora, no conjunto dos desdobramentos temáticos do terceiro c a pítulo, os dois últimos parecem destoar, na medida em que entram em cena informações que remontam a discussões que poderiam ser a gregadas a os capítulos a nteriores. É c la ro que isso não compromete a trama; apenas indica que, talvez, algo faça sentido em outro lugar.

O que se pode, porfim, destacar, é que um dos méritos do livro de Janine reside na articulação de diferentes fontes na tarefa de tecer histórias. A autora não encerra discussões em torno das temáticas propostas; a o contrário, contribui para indicar a pertinência, por assim dizer, de estudos que possam (re)atualizar indagaçõesacerca das relações que produzem
- apagamento das mulheres nas diferentes história s considera da s ofic ia is. So b re os interesses que estão em jogo, sobre o que se autoriza lembrar. Com certeza, Tensões, trabalhos e sociabilidades: histórias de mulheres em J oinville no século XIX é um livro significativo para os estudos sobre as histórias das mulheres e sobre as relações de gênero.

Notas

1 ' g oinville está localizada na região nordeste do Estado de Santa Catarina. A partir de 1851, com a instalação da Colônia Dona Francisca, vieram para essa região imigrantes suíç os, noruegueses e principalmente alemães. J oinville era a sede administrativa da colônia, que compreendia ta mbém parte das a tua is cidades de Garuva, Schroeder, Guaramirim, Campo Alegre e São Bento do Sul" (p. 13).

${ }^{2} \mathrm{O}$ livro loca liza-se no contexto de estudos sobre a história das mulheres; dentre outros, pode-se citar: Georges DUBY e Michelle PERROT, 1990; Mary DEL PRIORE, 1997; Antonio MORGA, 2001. Ca be ressa Itar que J a nine Gomes da Silva public ou, no livro organizado por Antonio Morga em 2001, um artigo intitulado "Lugares do recôndito, espaços de sociabilidade: histórias das mulheres imigrantes de J oinville". Destaca-se ainda que esse livro foi resenhado por Maria de Fátima Salum na Revista Estudos Feminista, v. 9, n. 2, p. 626-630, 2001.

\section{Referências bibliográficas}

DEL PRIORE, Mary (Org.). História das mulheres no Brasil. São Paulo: Contexto/UNESP, 1997.

DUBY, Georges; PERROT, Mic helle (Orgs.). História das mulheres no Ocidente. Porto: Edições Afrontamento; São Paulo: EBRADIL, 1990. 5 v.

MORGA, Antonio (Org.). História das mulheres em Santa Catarina. Florianópolis: Letras Contemporâneas; Chapecó: Argos, 2001.

Giovana llka Jacinto Salvaro Universidade Federal de Santa Catarina 